\title{
Design of High Intensity Impact Simulation Test Facility
}

\author{
T. Murali Mohan Raju ${ }^{1}$, Dr.M Radhakrishna ${ }^{2}$, Dr.A Krishnaiah ${ }^{3}$, S.Revanth ${ }^{4}$ \\ ${ }^{\prime}$ (Research Scholar, Mechanical Engg. Department,/Osmania University-,Hyderabad,Telangana India) \\ ${ }_{2}^{2}$ (Chief Scientist \& Head of Design Department,/CSIR-IICT-,Hyderabad,Telangana India) \\ ${ }^{3}$ (HOD, Mechanical Engg. Department,/Osmania University, ,Hyderabad,Telangana India) \\ ${ }^{4}$ (Student ME-CAD/CAM , MVSR Engineering Collegel Osmania University, India)
}

\begin{abstract}
Space vehicles will be subjected to high intensity impact during different stages of its course of application. High intensity explosive devices will be used in these vehicles for serving various functions like stage separation. These explosive devices will be attached to the space vehicles and once they are initiated high intensity impact will get produced due to explosion which will get transmitted to space vehicles. Sub systems of these space vehicles will be designed against this high impact loads. However design adequacy and functional working of these subsystems needs to be ensured before they become passengers of the space vehicles. It is a general practice to do the test by employing real environment explosive devices. But this means of testing calls for risk associated with explosion. Apart from this it also involves cost implication. Hence great need exists for alternative means which provides safe testing. The objective of this work is to design high intensity impact simulation test facility using mechanical means. It is proposed to drop hammer on the fixture and there by simulate the impact to the UUT mounted on the fixture. Initially hammer will be dropped due to gravity from certain height in order to gain the velocity and there by impact. Impact energy will be proportional to velocity and in turn depends on drop height. All the subsystems of the proposed design will be designed and accordingly their respective dimensions will be worked out.
\end{abstract}

Keywords: Design configuration, Simulation, Spacecraft etc.

\section{Introduction}

Sub systems of the space vehicles will be designed against the high impact loads which are anticipated during their course of application. However design adequacy and functional working of these subsystems needs to be ensured before they become passengers of the space vehicles. It is a general practice to do the test by employing real environment explosive devices. But this means of testing calls for risk associated with explosion. Apart from this it also involves cost implication. Hence great need exists for alternative means which provides safe testing. The objective of this work is to design high intensity impact simulation test facility using mechanical means.

Numerous pyrotechnic devices are used in aerospace vehicles to accomplish initiation, release, severance/fracture, jettison, valving, switching, time delay, and actuation process. The initiation of these devices generates severe shock, which has been overlooked as a potentially damaging environment in many equipment specifications. This severe shock is referred to as pyroshock which is characterized by transient high acceleration and high frequencies [1]. Today's Aerospace vehicles utilize numerous pyrotechnic devices to separate structural subsystems, deploy appendages and activate onboard operational subsystems. The firing of these pyrotechnical charges generates severe impulsive loads (so-called pyroshocks) that can cause failures in electronic components [2]. Sandia National Laboratories (SNL) designs mechanical systems with components that must survive high frequency shock environments including pyrotechnic shock. These environments have not been simulated very well in the past at the payload system level because of weight limitations of traditional pyroshock mechanical simulations using resonant beams and plates [3]. Pyroshocks are structural responses to transient excitation caused by the essential use of pyrotechnic devices in aerospace applications. In order to avoid damage in aerospace structures due to pyroshocks, tests are performed on earth prior to launching space modules. In these tests, explosive loads are often replaced by alternative excitation methods such as hammer pendulums or shakers simulating on earth the impact taking place in space [4]. Spacecrafts are subject to recurrent high frequency, high amplitude shocks over their lifetime. These shocks have been known to cause failures in systems leading to total or partial loss of entire space missions. With new launch vehicles the shocks are getting more frequent and more severe. Launch vehicle manufacturers are striving to keep as much mass as possible available for value adding payload, so damping materials are kept to a minimum [5]. Mechanical shocks induced by the detonation of pyrotechnics ordnances are known to be highly detrimental to the integrity of spacecraft components. As a result, it is desirable to qualify these components as early as possible to prevent failures during launch. Assembly-level shock tests are usually performed on these components [6]. Launch vehicles and spacecraft's use a certain number of pyrotechnic devices during their missions. During flights, stages and boosters separation of the launcher are performed by means of fast cutting devices using high 
explosive charges (electro-explosive devices or EED). Detonation of these cutting devices produces a so-called pyrotechnic shock which causes the dynamic loading of the launcher structure and its components. In order to

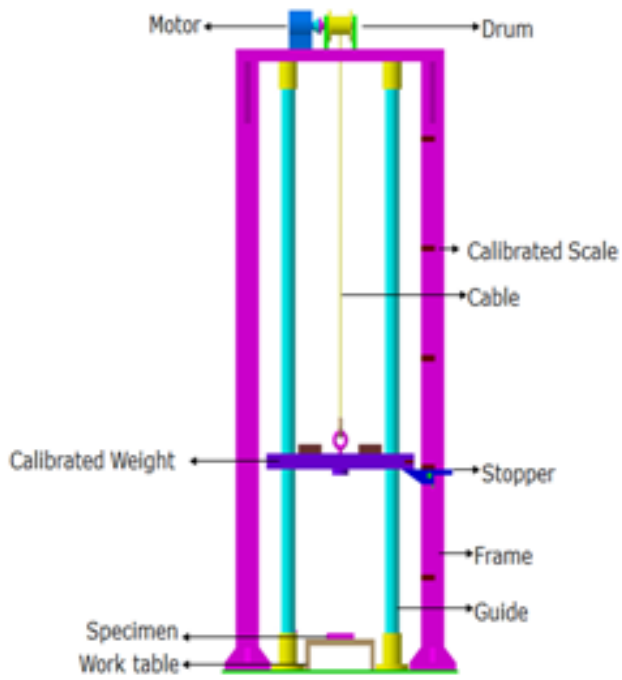

Fig. 1 Proposed design configuration

verify critical components, such as electro pneumatic components, it is necessary to perform pyrotechnic shock qualification tests [7]. Pyroshock is a potentially severe environment produced by the detonation of explosively actuated components and stage separation hardware. Electronic components exposed to pyroshock events during flight or deployment can be damaged by this high frequency, high $\mathrm{G}$ shock. Flight qualification of these components may be accomplished using one of many existing techniques to simulate the pyroshock environment in the laboratory [8]. Satellite faces many extreme types of loading throughout their life time from the harsh launch environment to the critical space environment. Launch load mainly dynamic is the main design concern for space structure. Shocks are the one of the most critical dynamic load occurs in spacecraft. Optics Mirror Assembly (OMA) is used in the telescope of the satellite [9].

As can be seen, most of the test facilities needs high pressure air of the order of 350 bar for its operation. Drawback with this set up is explosion risk associated with such high pressure. Controllability and repeatability of metal to metal impact simulation are appeared to be poor. Linear Shaped Charge (LSC) makes use of explosive means and it calls for high explosion risk Simple to grasp and implement.

Based on the limitations brought out as an outcome of literature review it is observed that a great need exists for design of high intensity impact simulation test facility using mechanical means.

- $\quad$ Maximum acceleration $=20000 \mathrm{~g}$

\section{Specifications}

- $\quad$ Desired FOS $=1.5$

\section{Design Philosophy}

It is proposed to drop hammer on the fixture and there by simulate the impact to the UUT mounted on the fixture. Initially hammer will be dropped due to gravity from certain height in order to gain the velocity and there by impact. Impact energy will be proportional to velocity and in turn depends on drop height. Later on other means of enhancing velocity by actuating hammer in addition to gravity while focusing on its effect on increasing the impact will also be explored. Proposed design configuration is as shown in Fig.1.

\section{Working Principle}

- Calculate Loads to be attached from the energy requirements

- Attach necessary Weights when mechanical stopper is engaged

- Place the specimen on the work table

- Take the weights to required calibrated height with the help of motor

- Disengage the mechanical stopper

- Disengage the clutch

- Weight falls freely on the specimen

- Limit switch activates the motor as soon as the impact occurs 
- Weight is retracted till the mechanical stopper.

Position of limit switch in the proposed configuration is shown in figure 3.3.

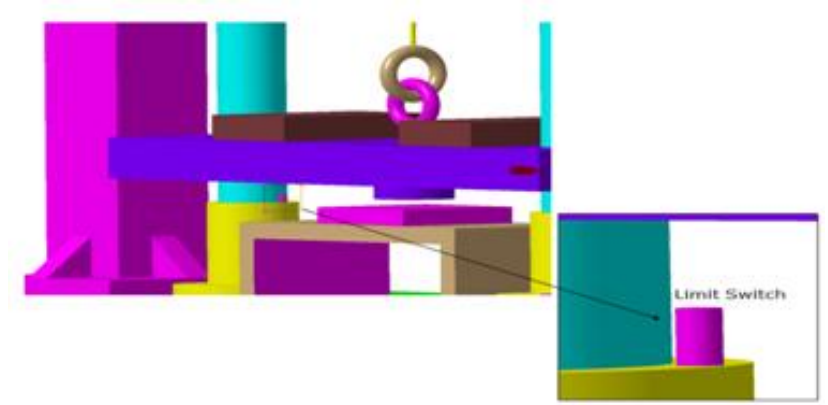

Fig 3.3 Position of limit switch in the proposed configuration

Proposed configuration in two instances is shown in Fig. 4

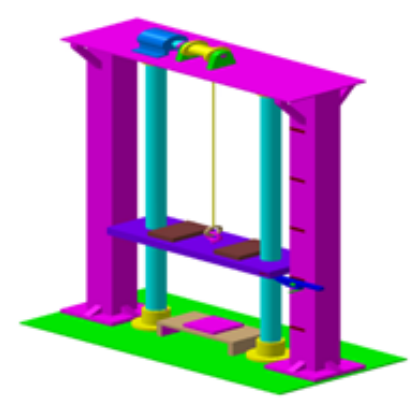

Before hammer is dropped after hammer is dropped

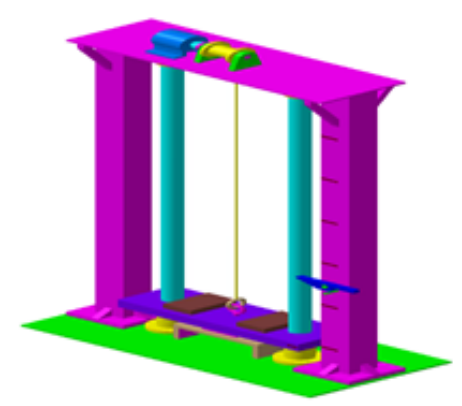

Figure 3.4 Proposed design configurations

Foot print of motor and drum (Consisting of clutch, pulley and rope) are shown in figure 3.5

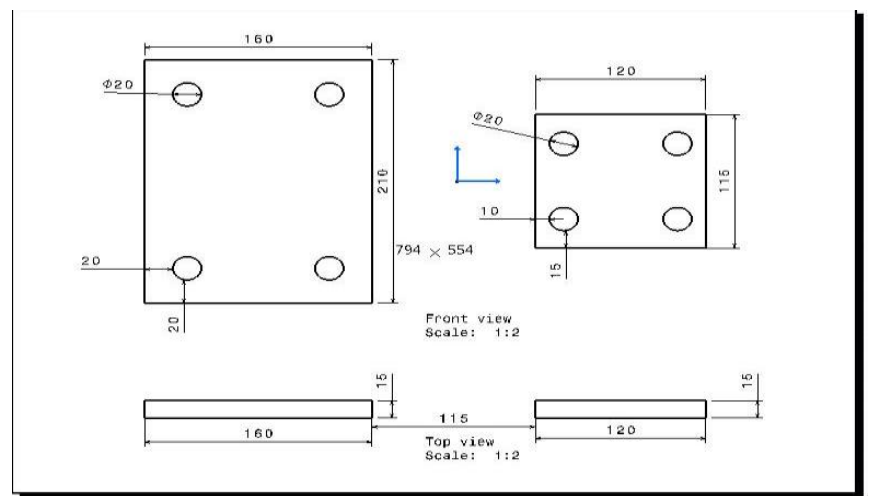

Figure 3.5 Foot print of motor and drum

\section{Sizing of Design Configuration}

Total drop height is considered as $7 \mathrm{~m}$. I-section is considered for the frame keeping in view its following advantages.

- High moment of inertia hence high bending resistance

- High energy dissipation (Damping)

- For the same overall geometry it possesses least weight

Following standard dimensions are chozen for I-section.

- $\quad$ Height $=200 \mathrm{~mm}$

- $\quad$ Width $=100 \mathrm{~mm}$

- Thickness of flange $=7.3 \mathrm{~mm}$

- Thickness of web $=5.4 \mathrm{~mm}$ 
Its cross sectional view is shown in figure 3.5

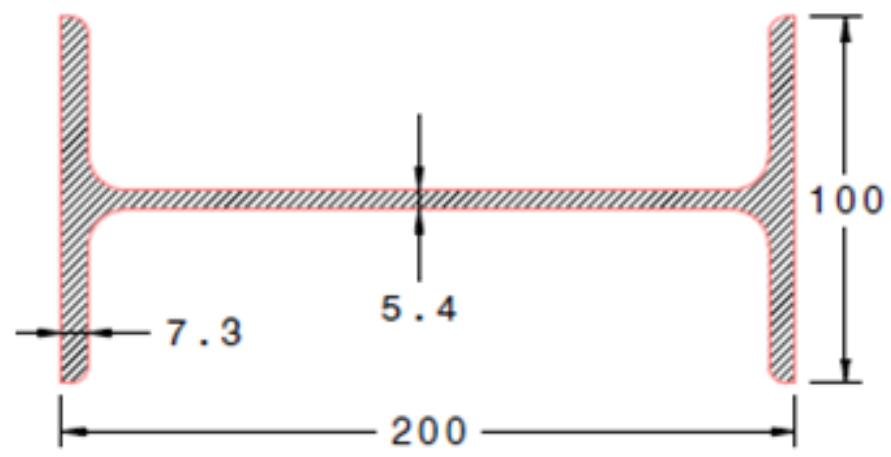

Figure 3.5 Cross sectional view of I-section for frame

Hollow circular cross section is considered for the guides and the same is shown in figure 3.6.

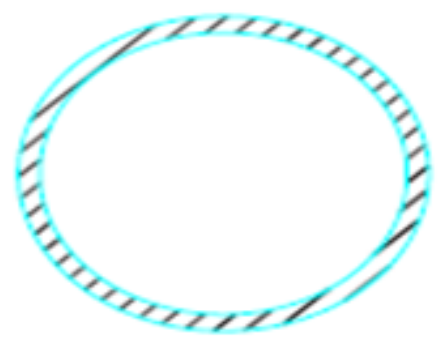

Figure 3.6 Cross sectional view for guide

Following standard dimensions are chozen for hollow circular cross section.

- $\quad$ Outer diameter $=50 \mathrm{~mm}$

- $\quad$ Thickness $=10 \mathrm{~mm}$

Keeping inter distance between two frames to accommodate specimen along with its work table and the footprints of motor and drum following dimensions are considered for top plate.

- $\quad$ Cross section = Rectangular

- $\quad$ Length $=2600 \mathrm{~mm}$

- $\quad$ Width $=600 \mathrm{~mm}$

- Thickness $=20 \mathrm{~mm}$

\section{Summary of Design}

Parameters pertaining to motor are summarized in Table 5.1.

\begin{tabular}{|c|l|c|}
\hline $\begin{array}{c}\text { Sl. } \\
\text { No. }\end{array}$ & Design Parameter & Value \\
\hline \multicolumn{2}{|c|}{ MOTOR } & 3 phase induction \\
\hline 1. & Type & $5 \mathrm{HP}$ \\
\hline 2. & Power & $25 \mathrm{~N}-\mathrm{m}$ \\
\hline 3. & Torque & $750 \mathrm{rpm}$ \\
\hline 4. & Speed & $415 \mathrm{~V}$ \\
\hline 5. & Voltage & $7.5 \mathrm{~A}$ \\
\hline 6. & Current & $40 \mathrm{~kg}$ \\
\hline 7. & Weight & \\
\hline
\end{tabular}

Table 5.1 Summary of parameters - Motor 
The design parameters pertaining to frame are summarized in Table 5.2.

\begin{tabular}{|c|l|c|}
\hline $\begin{array}{c}\text { Sl. } \\
\text { No. }\end{array}$ & \multicolumn{1}{|c|}{ Design Parameter } & Value \\
\hline \multicolumn{2}{|c|}{ FRAME } \\
\hline 1. & Length & $7 \mathrm{~m}$ \\
\hline 2. & Cross section & I-section \\
\hline 3. & Height of I-section & $200 \mathrm{~mm}$ \\
\hline 4. & Width of I-section & $100 \mathrm{~mm}$ \\
\hline 5. & Thickness of flange & $7.3 \mathrm{~mm}$ \\
\hline 6. & Thickness of web & $5.4 \mathrm{~mm}$ \\
\hline
\end{tabular}

Table 5.2 Summary of design parameters - Frame

The design parameters pertaining to guide are summarized in Table 5.3.

\begin{tabular}{|c|l|c|}
\hline $\begin{array}{c}\text { S1. } \\
\text { No. }\end{array}$ & Design Parameter & Value \\
\hline GUIDE & \\
\hline 1. & Cross section & Hollow circular \\
\hline 2. & Outer diameter & $50 \mathrm{~mm}$ \\
\hline 3. & Thickness & $10 \mathrm{~mm}$ \\
\hline
\end{tabular}

Table 5.3 Summary of design parameters - Guide

The design parameters pertaining to top plate are summarized in Table 5.4.

\begin{tabular}{|c|c|c|}
\hline $\begin{array}{c}\text { Sl. } \\
\text { No. }\end{array}$ & Design Parameter & Value \\
\hline \multicolumn{3}{|c|}{$\underline{T O P} P L A T E$} \\
\hline 1. & Cross section & Rectangular \\
\hline 2. & Length & $2600 \mathrm{~mm}$ \\
\hline 3. & Width & $600 \mathrm{~mm}$ \\
\hline 4. & Thickness & $20 \mathrm{~m}$ \\
\hline
\end{tabular}

Table 5.4 Summary of design parameters - Top plate 


\section{Conclusion}

Preliminary design configuration of high intensity impact simulation test facility using mechanical means is accomplished as an outcome of this research work.

\section{Acknowledgements}

This research is supported by Science and Engineering Research Council (SERC), Department of Science and Technology (DST) New Delhi, INDIA. (SR/SR3/MERC-098/2007)

\section{References}

[1] Jung, et.al. "Review of pyroshock wave measurement and simulation for space systems", Science Direct, Volume 45, Issue 4, Pages 631-642, May 2012.

[2] Enrico FILIPPI, "Pyroshock Simulation Using The Alcatel Etca Test Facility”, Launch Vehicle Vibrations. First European Conference, Dec. 14-16, 1999.

[3] Vesta I. Bateman, et.al. “JXgh Frequency Mechanical Pyroshocks Simulation for Payload Systems”, OSTI technical report, 1999.

[4] Behnam Houshmand, "A novel excitation method for pyroshock simulation", Journal of vibration and control, 2014.

[5] Martin Johnson, "Development of a Shock Test Facility for Qualification of Space Equipment", MS thesis, Department of Applied Mechanics Division of Dynamics, Chalmers University of Technology, 2012.

[6] Jean-Philippe Deblois, "Analytical and Experimental Investigation of Overtesting during Assembly-Level Shock Testing”, MS Thesis, Concordia University, 2009.

[7] J.-M. Ndambi, "Numerical simulations of a pyrotechnic shock test", Proceedings of the 8th International Conference on Structural Dynamics, EURODYN 2011, Leuven, Belgium, 4-6 July 2011..

[8] Davie, N. T.; Bateman,, "Recent developments in pyroshocks simulation using fixtures with tunable resonant frequencies", Conference [Proceedings, Annual technical meeting and exposition of the Institute of Environmental Sciences, Rosemont, IL (United States), 1994.

[9] Brijesh Kumar Patel, "Shock Simulation of the Optics Mirror Assembly By Numerical Method", Int. Journal of Engineering Research and Applications, Vol. 5, Issue 9, (Part - 3), pp.119-123, 2015. 